\title{
PEER REVIEW
}

\section{DAS BEGUTACHTUNGSVERFAHREN FÜR \\ FORSCHUNGS-FACHBEITRÄGE IN ATZ, MTZ UND ATZ ELEKTRONIK}

\begin{tabular}{lll} 
LENKUNGSAUSSCHUSS & \\
\hline Prof. Dr.-Ing. Lutz Eckstein & RWTH Aachen University & $\begin{array}{l}\text { Institut für } \\
\text { Kraftfahrzeuge Aachen }\end{array}$ \\
\hline Prof. Dipl.-Des. Wolfgang Kraus & HAW Hamburg & $\begin{array}{l}\text { Department Fahrzeugtechnik } \\
\text { und Flugzeugbau }\end{array}$ \\
\hline Prof. Dr.-Ing. Ferit Küçükay & $\begin{array}{l}\text { Technische Universität } \\
\text { Braunschweig }\end{array}$ & Institut für Fahrzeugtechnik \\
\hline Prof. Dr.-Ing. Stefan Pischinger & RWTH Aachen University & $\begin{array}{l}\text { Lehrstuhl für } \\
\text { Verbrennungskraftmaschinen }\end{array}$ \\
\hline Prof. Dr.-Ing. & Universität Stuttgart & $\begin{array}{l}\text { Institut für Verbrennungs- } \\
\text { motoren und Kraftfahrwesen }\end{array}$ \\
\hline Hans-Christian Reuss & Karlsruher Institut für Technologie & Institut für Kolbenmaschinen \\
\hline Prof. Dr.-Ing. Ulrich Spicher & Technische Universität Dresden & $\begin{array}{l}\text { Lehrstuhl für } \\
\text { Verbrennungsmotoren }\end{array}$ \\
\hline Prof. Dr.-Ing. Hans Zellbeck & & \\
\hline
\end{tabular}

\section{GUTACHTERAUSSCHUSS}

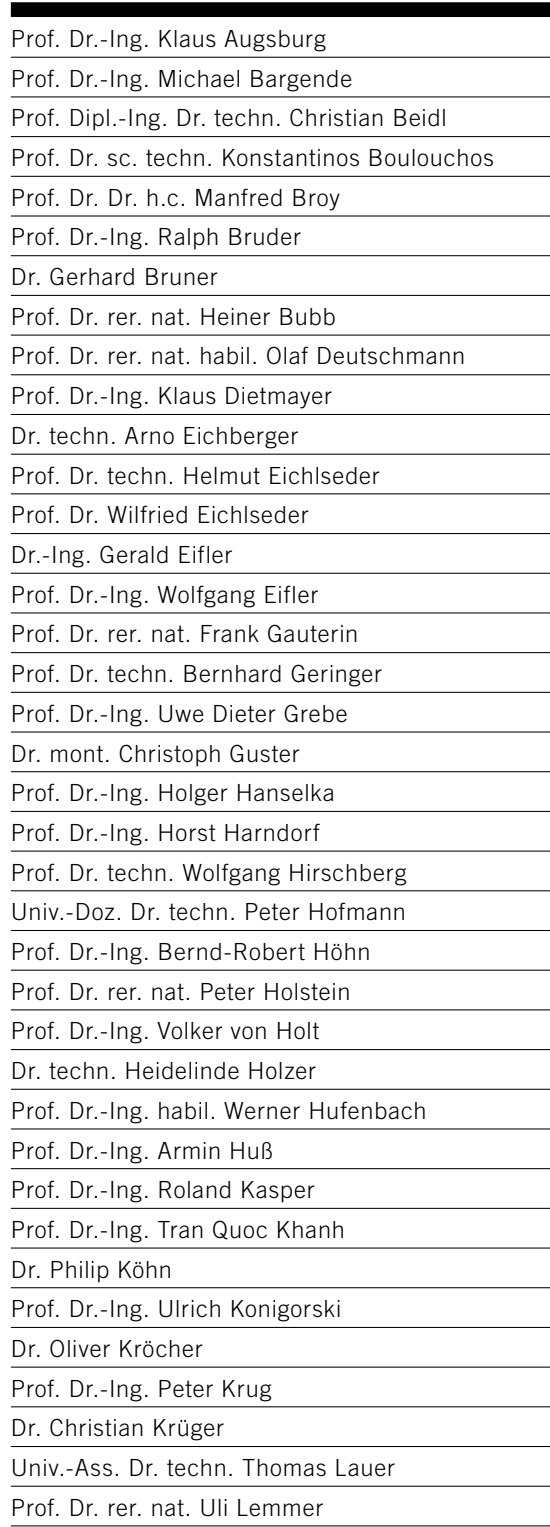

Wissenschaftliche Beiträge der Hochschulen für ATZ Automobiltechnische Zeitschrift, MTZ Motortechnische Zeitschrift und ATZelektronik durchlaufen ein Begutachtungsverfahren, den „Peer Review Process" (zu Deutsch etwa: Begutachtung unter Fachkollegen). Wissenschaftler aus Forschung und Industrie prüfen vor der Veröffentlichung die Fachbeiträge, die von der Redaktion angenommen wurden. Mit dem Peer-Review-Verfahren wird zum einen für die Leser die Qualität als führende wissenschaftliche Zeitschriften der Fahrzeug- und Motorentechnik sowie Elektronik gesichert und zum anderen den Autoren eine unter Wissenschaftlern anerkannte Publikationsplattform geboten.

Und so funktioniert die „Peer Review“ in der Praxis: Ein Fachbeitrag geht in der Redaktion ein. Zwei Experten aus dem Gutachterausschuss prüfen die Arbeit. Kommen diese Fachleute nicht zu einem einheitlichen Urteil, steht ein Mitglied des Lenkungsausschusses als Schiedsrichter zur Verfügung. Nach Korrekturempfehlungen der Experten und der Überarbeitung durch den Autor ist der Beitrag dann angenommen und wird veröffentlicht.

Das Peer-Review-Verfahren von ATZ und MTZ wurde 2008 von der WKM Wissenschaftliche Gesellschaft für Kraftfahrzeugund Motorentechnik e.V. bei der DFG Deutsche Forschungsgemeinschaft zur Anerkennung gebracht. Die ATZelektronik nimmt am Peer Review seit 2011 teil. 